\title{
DESIGN CRITERIA FOR OPTIMIZATION OF THE CROSS IGNITION PROCESS IN GAS- TURBINE-ENGINES
}

\author{
Dr.-Eng. Mazen Abu Amro' ${ }^{1}$, Dipl.-Eng. Ali Imara ${ }^{2}$ and \\ Prof. Dr. Samy S. Abu Naser ${ }^{3}$ \\ ${ }^{1}$ Faculty of Engineering and Information Technology, Al Azhar University, Gaza \\ ${ }^{2}$ Palestinian Airlines, Quality Insurance Department, Gaza \\ ${ }^{3}$ Faculty of Engineering and Information Technology, Al Azhar University, Gaza
}

\begin{abstract}
Reducing of pollutants with simultaneous increase of the gas turbine power, is always a fundamental aim of the Turbine technology. New developed structures and operating systems in the turbine production have been established. In the meanwhile, burning instabilities are still appearing in these systems during a Cross-ignition process (CI), creating pollutants due to high flame temperatures, and are not yet completely investigated.
\end{abstract}

The phenomena of a CI is taking place during operation of malty-burner combustion chambers, when one burner is extinguished and a particular volume of combustible mixture is formed in the distance between this burner and the adjacent lightened one, which considered to be as an ignition path.

Cross ignition process should be performed along the ignition path in a particularly controlled small time. So that, no excessive quantities of combustible mixtures will be injected during this time in the combustion chamber. Otherwise, burning instabilities and mechanical wear will be occurred.

Depending on this illustration, the Cross Ignition Time (CIT) of an extinguished burner, that will be considered as the evaluation measure for the entire cross-ignition process, should be Possibly as low as its normal ignition time.

The main objective of this project is to reproduce constructive criteria for controlling of cross ignition process by influencing the mixing process and heat flux in a defined mixing zone existing along the ignition path.

\section{KEYWORDS}

Malty-Burners, Liquid fuel, Cross- Ignition, Heat Flux, Numerical-Modelling

\section{INTRODUCTION}

High inlet turbine temperature is still essential for increasing the Gas turbine power. This aim had been achieved by developing combustors with several individual burners, or with several individual flames, each with an individual lower flame- temperature. Thus, the entire performance of a large combustors, required for a desired inlet turbine temperature, was distributed to several smaller individual burners (malty- burner combustors shown in Fig. 1) with smaller flames, so that less pollutants were then produced. 
In these developed malty- burner gas turbines arise sometimes ignition difficulties, occurred during transfer of ignition light from a burner to the adjacent extinguished one, are not yet fully overcome.

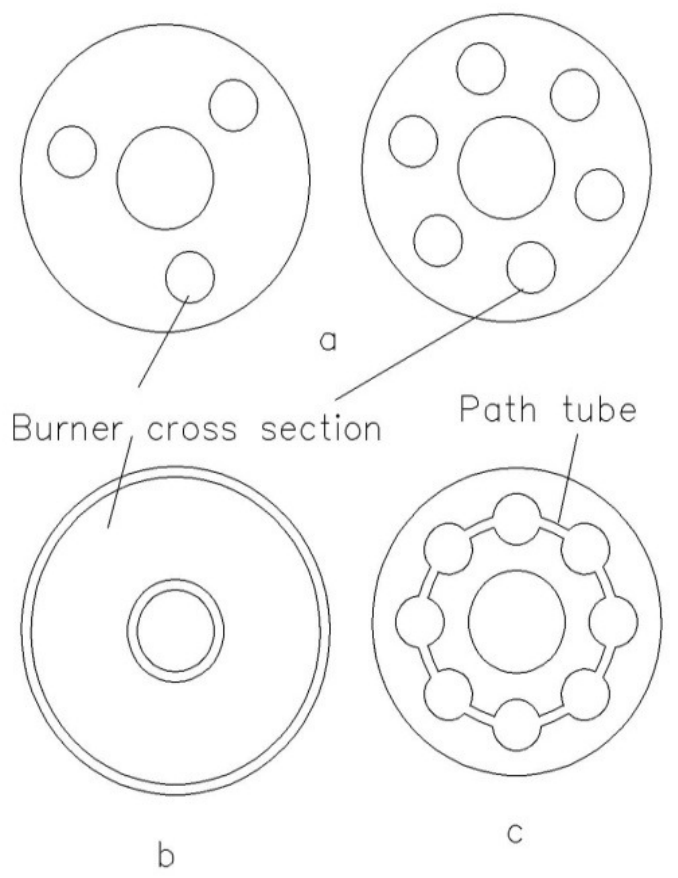

Fig. 1: (a) malty-burner without path tubes (b) an annular- combustion chamber (c) malty-burner combustors with path tubes

However, in the start ignition process, the burners are put into operation by an auxiliary ignition spark and/or an auxiliary flame according to a special mechanism [1]. During the operation of combustors, burners that extinguished by briefly interruption of fuel supply should be quickly reignited through the adjacent operating burners under various critical conditions without additional aids (e.g. Pilot flame), before an excessive air/fuel mixture is accumulated in the combustion chamber. Otherwise, unstable combustion would be occurred in case of delaying the re-ignition process.

This phenomenon of cross-ignition requires in practice, hot combustion gases and emissions flowing through connecting passages to the extinguished burner. Heat flux will then spread into this burner, until the injected cold mixture in this burner is appropriate for a cross-ignition to be carried out. Thus, determination of CIT is high important for accomplishing a smooth re-ignition. Several combustion studies have been yet established about cross-ignition based on controlled turbulent mixing processes.

Due to the above-mentioned mechanisms of cross- ignition, considerations will be established for controlling constructive influence parameters on cross ignition, seeking to examine distinctive constructive parameters, that controlling the mixing zone between burners and influencing the cross ignition process. Whereby, optimized operating conditions will be identified through variation of the parameters that lead comparably to reduce the CIT, and meanwhile to increase the gas turbine power. 
A simple theoretical model is derived to calculate the CIT of the cross ignition process throughout the heat balance equations along the ignition path, and simultaneously identify the influence parameter for the occurred cross-ignition process. The following parameters are adopted in this study as distinctive parameters in the heat balance equations that govern the heat flux during operation of the cross-ignition:

- The contact area between flame and an adjacent mixture.

- The flow velocity and swirl intensity of the burner mixture- jet.

- The distance between each two burners.

Finally, the influence parameters and their interaction are identified, so that design criteria can be developed in new concepts for controlling the entire cross-ignition process.

\section{LITERATURE REVIEW}

The phenomenon of cross-Ignition between turbulent mixture jets and adjacent ignition source has not yet been fully investigated. There are very few publications that targeted the problem addressed here, where many of these scientific studies have examined this problem within relative operations mainly like flame extinction and flame stabilization.

M. Boileau [6] had established a direct study to calculate the CIT, presenting a simulation for the flame topology in 3D, using the Large Eddy Simulation (LES) at a combustion chamber (VESTA Turbomeca with 18 burners) with full contact burners. He showed that the injection rate has a strong influence on the CIT. As he had discovered, that the transmission rate of a burner flame to the next one is higher than the flame speed, he divided the chamber into sectors and calculated the CIT from a sector to the next one.

In this work, it is possible to examine the cross ignition by varying the contact area and the distance between individual burners on a simplified model. Flame extinction and stabilization are also occurred in the Combustion Chamber (CC) due to high turbulent beaks and high speed fluctuations of the mixture jets, so that a re-ignition for the relevant burner is then required[3].

According Warnatz,[3] the flame near an extinction is sensitive and is affected by the ratio of the molecular heat- and mass transport. They also found out that the flame is stretched or blown out at sufficient high discharge velocity of the air $(\chi)$, and the strong stretch of flame fronts leads to local extinctions that are built-up together and can then lead to a total extinction of the main flame. Fig. 2 of shows different flame front forms. He defined the stretching speed as by the relationship $(\mathrm{a}=2 \chi / \mathrm{R})$. Whereby, $(\mathrm{R})$ in this case refers to the nozzle diameter and $(\chi)$ to the critical discharge velocity of the air at burner mouth. Thus, $(\chi)$ and $(\mathrm{R})$ are both affecting the Reynolds number of the mixture jet. 


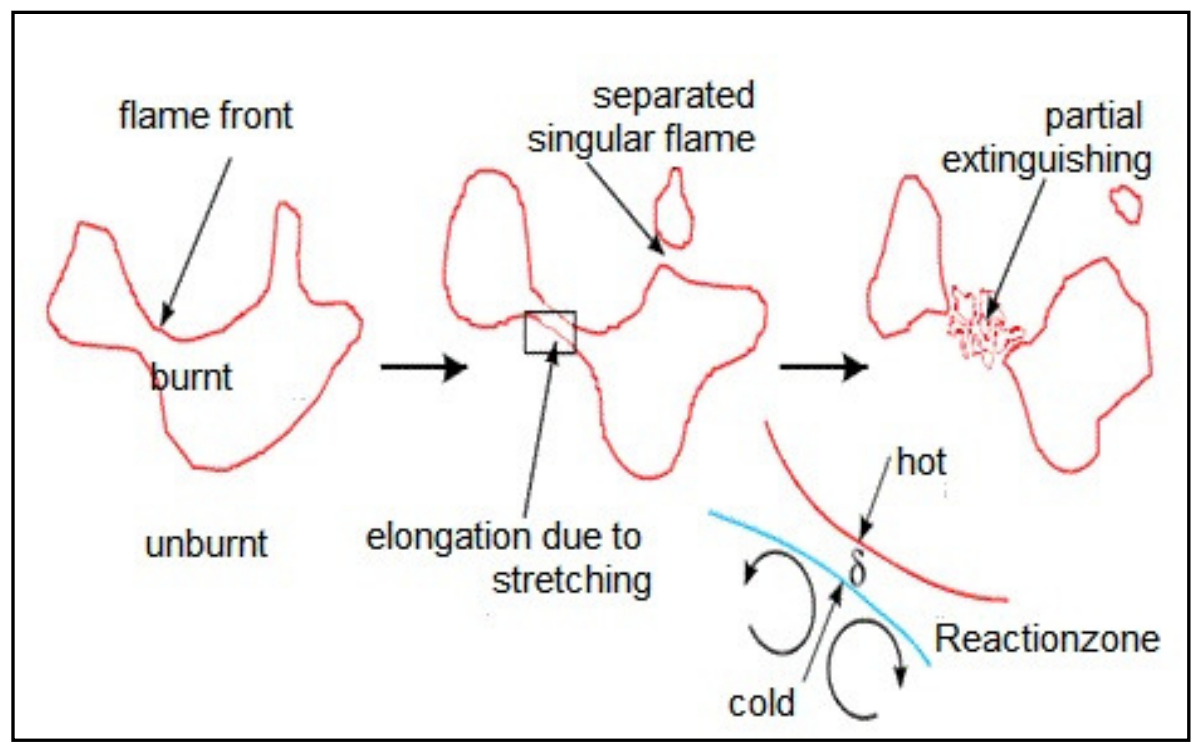

Fig. 2: Illustration of flame front forms, stretching and local extinction [8].

They have also asserted that this extension depends on the mixture composition and the equivalence ratio $(\Phi)$ of the mixture. I.e. any re-ignition of the occurring extinction is influenced by these two parameters $\chi, \Phi$. These results has [9] exploited and continue to examine the impact of the pilot gas addition on the cross-ignition limits experimentally by using a three- burner experimental setup. He depended on the mixture ratio of individual burners and on the variation of the pilot fuel ratios of every adjacent burner, using a general quantitative methodology to describe the combustion properties of the mixture in different operating conditions, where a mixing model was represented to control the cross-ignition limits in a combustion chamber relative to the mixing behaviour of the burner. But, without determination of the cross-ignition time CIT, Moreover, an important part of this study is to exploit these findings to examine the cross-ignition due to variation in the discharge velocity of the air $\chi$, which will be represented by the Reynolds number of the incoming air in the CC.

During re-ignition and flame transfer occur often thermo acoustic fluctuations that have been examined by Klaas Kunze [10] on a single- and Annular combustor configurations. He found out that these fluctuations are taking place duo to the resulting pressure waves formed by unstable ignition- and flame transfer operations. Following these indexed pressure waves, small local ignitions are occurred in various places along the ignition path, and are considered as a preignition for the main cross- ignition process.

He has introduced a flame transfer function to describe these waves, discovering that the resulting fluctuations form are dependent on the turbulent mixture composition. Furthermore, he was able to control the stabilization of the ignition transfer, based on structural modifications in the combustion chamber, by partially addition of pilot gas portion in the burner, and had focused on the composition of the incoming mixture jet.

Kunze and Jordan [2] have also demonstrated that the tendency of the flame contour and the different relative velocities of flame front are both dependent on pilot fuel supply- and air ratio. In the meanwhile, they have found that the flame thickness and flame contour play a major role in heat- and mass transfer between burnt- and fresh mixture, since they affect the distance between 
the flame (which considered as an ignition source) and the adjacent mixed jet. It mean for this work that the CI-speed of the unburned mixture is influenced by heat and mass transfer. Consequently, it is possible to influence the flame thickness and flame contour by swirling the mixture of both jets for getting more intensive heat and mass transfer.

Yassin Fritz [7] has also confirmed this correlation between forming of flame contour and flame front speed with the swirl intensity. I.e. by using adjustable swirl generators, like radial grids with sliding segments at the burner outlet, different swirl strengths could be achieved causing different flame expansions. This would lead to control the flame cross section diameter and the mixture jet. Thus, the flame diameter will be as a predominant factor of the cross-ignition in this study, so that the distance between burners in a combustion chamber can be designed according to technical requirements. During this work the swirl intensity for the cross-ignition could be examined by introducing different swirl guide blades with different twist angles during each experimental set up.

It was also noticed, that while performing of high-speed imaging for the flame, the longitudinal distribution of the stationary heat release in the flame play an important factor in flame discretization. Kunze and Jordan [2] has defined the ignition point by comparing between the 2dimensional optical measurements of the radicals and the temperature distribution curves using the top occurring gradients of the curves, Fig. 4.

Kunze has recorded the quantitative current heat release of the flame, using the $\mathrm{OH}$ - radiation technical measurements. He considered the average radiation intensity as a measure for the present $\mathrm{OH}$ - radicals, which in turns makes a quantitative statement about the current heat release from the flame zone.

In this paper, the chemical heat release from the ignited mixture and from the adjacent flame should both be put into consideration and be calculated through the heat balance equations for the case of completely determining the CIT. 


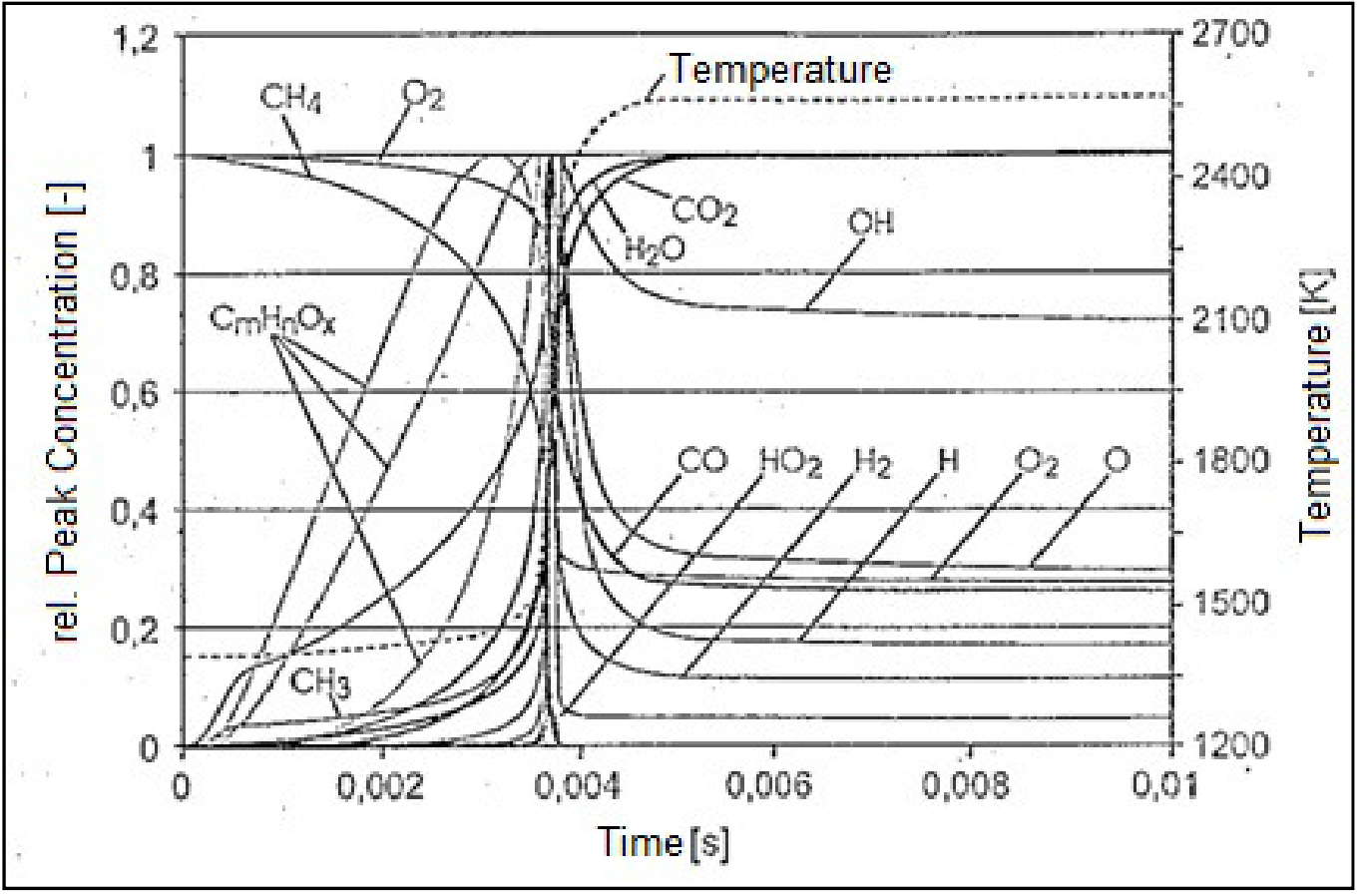

Fig. 4: Calculated temperature and species gradients at 7.0 vole\%,CH4 flame (CHEMKIN II) [2]

\section{PROBLEM AND STRATEGY OF THE STUDY}

In this study, a turbulent mixture jet in various specific ratios is examined for cross ignition under varied operating conditions. Where a virtually mixing zone is established along the ignition path, in which a combustible mixture is created as a result of turbulent exchange mass flow (ms), see in Fig. 5. Through this created mixture a cross-ignition is to be transported along the mixing zone to the cold mixture.

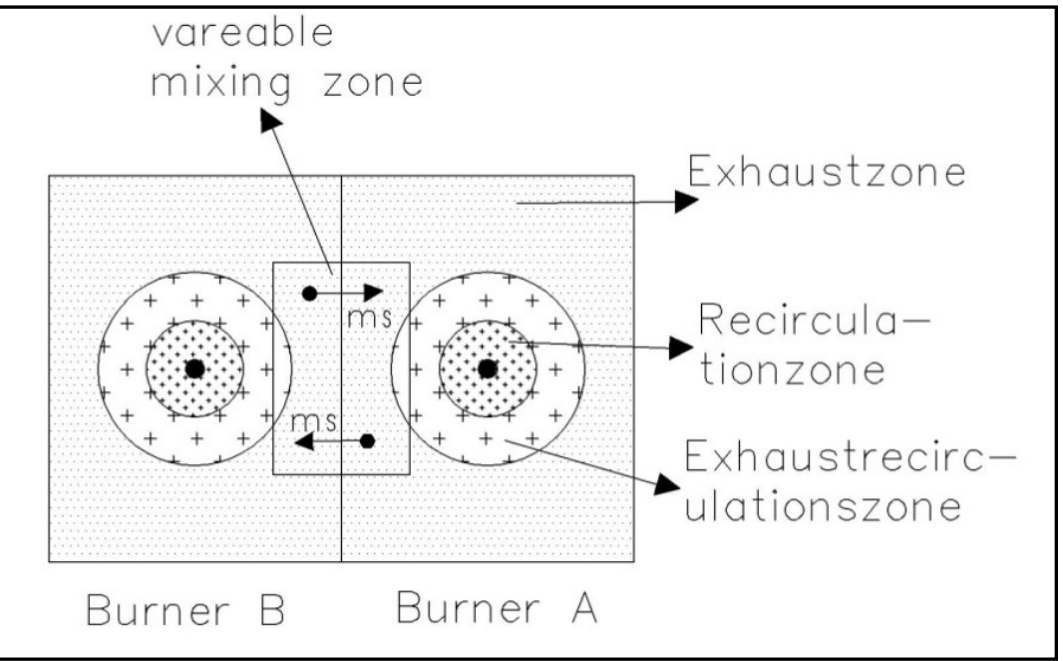

Fig. 5: Representation of the exchange mass flow $\left(\dot{\mathrm{m}}_{\mathrm{s}}\right)$ between two turbulent jets. 
Previous studies had identified different flame zones of an individual Brenner illustrated in Fig. 6. Mainly, the fuel- and combustion air jet, the exchange processes of the mixture jet with its surrounding, and a variable control volume as part of the mixing zone.

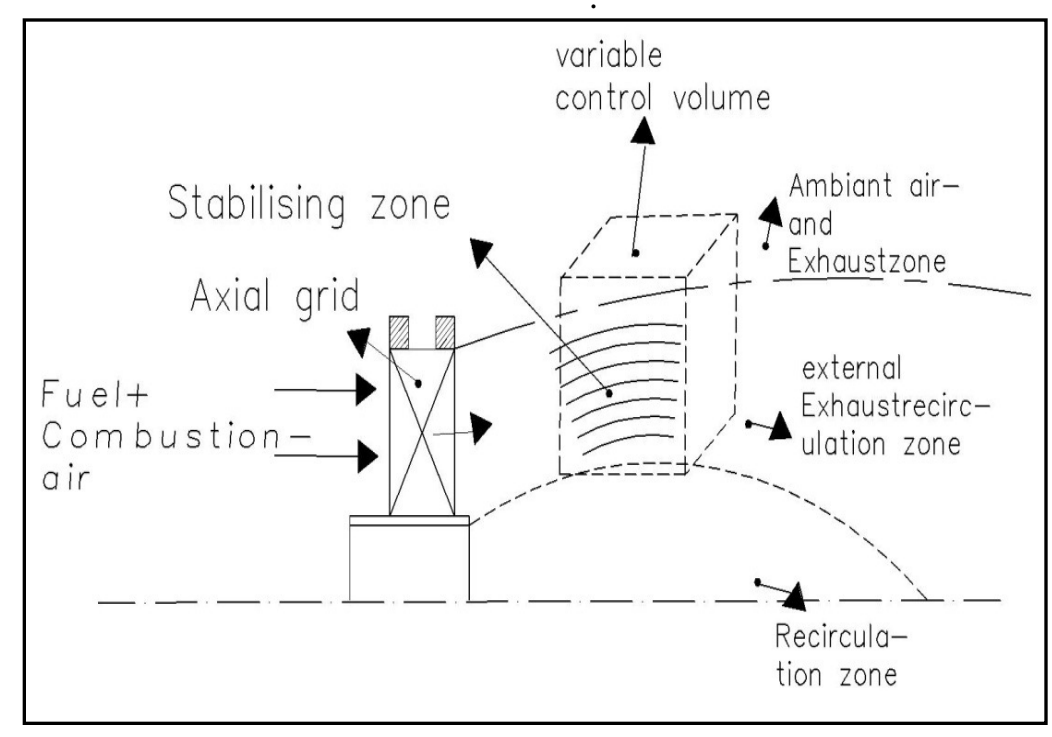

Fig. 6: Illustration of different flame zones [4]

The mixture composition in the mixing zone is of a particular importance, since it determines largely the global behaviour of the occurred cross ignition, determining particularly the CIT, and controlling the turbulent mixing process.

Based on physical principles, more intensive exchange processes will be carried out on the mass flow between the two zones, as a result of the structural influencing parameters. Consequently, a combustible composition will consist in a specific time providing a cross-ignition.

The velocity of individual burner mixture jet is physically an impact for the wide of the flame expansion diameter [6]. This velocity defines in turn the distance between the flame and the outer contour of the adjacent mixture jet in the CC. So the exchange flow rate (ms) between the two jets can be varied, and its impact on cross-ignition will be subsequently analyzed. The dimension of the mixing zone is metered by varying of the path flow area between the two burners.

An a preliminary model is shown in Fig. 7, that illustrates the heat flux throughout the mixing zone, and the expected heat losses on the system. The heat balance equations for the theoretical calculation of the CIT will be created in this paper for a specific control volume (Vcontr.), as part of the entire mixture- flow injected during a calculated CIT.

Based on Newton's law, significant heat losses are meanwhile taking place through exterior walls and exhaust gas mass flow, that are to be subsequently taken into account in any relevant balanceequations. 


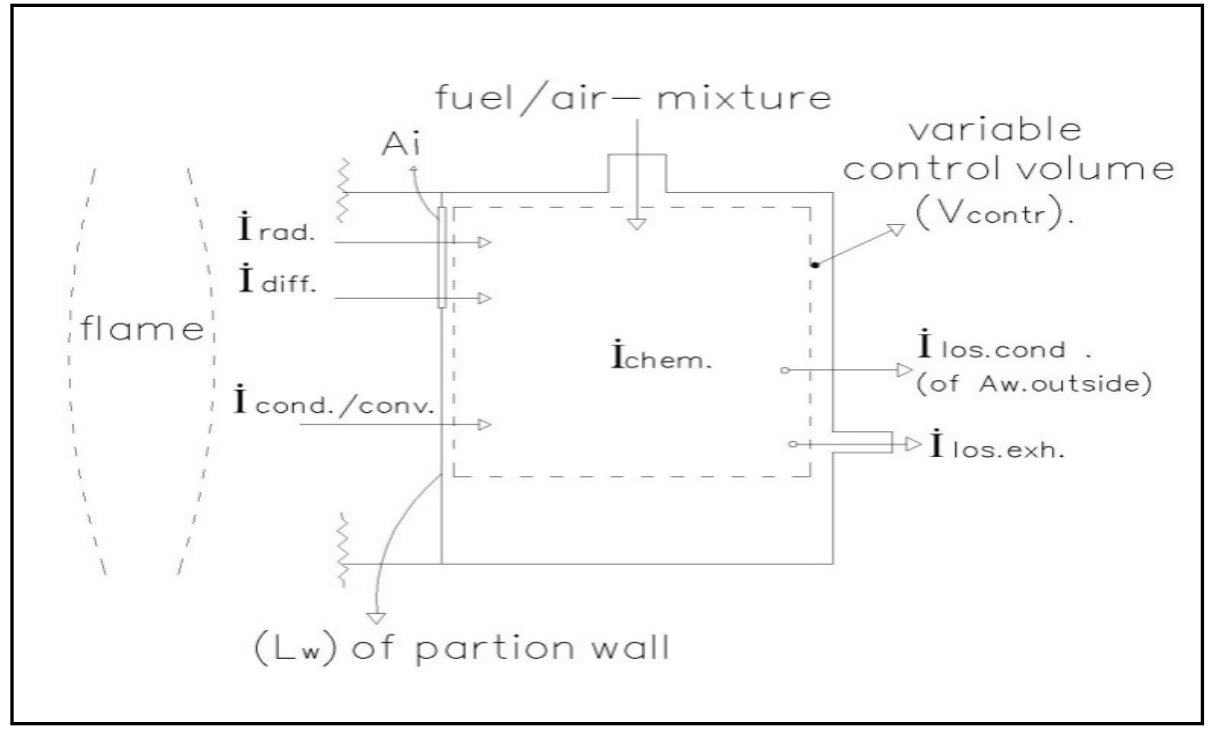

Fig. 7: Schematic of the heat balance between flame and adjacent mixture jet illustrated on a control volume $\left(\mathrm{V}_{\text {contr. }}\right)$ of the adjacent mixture.

\section{THEORETICAL DETERMINATION OF CROSS-IGNITION TIME}

The energy required for re-ignition of a fuel/air mixture jet in a cold burner, adjacent to an operating flame during combustion, is mainly provided by turbulent heat and mass diffusion flux through exchanges between the two burners, along a turbulent mixing zone. Thus, the heat transfer carried out by radiation, emission from the flame and by conduction and convection through the adjacent walls are here distinguished by the heat balances, and are determined in the theoretical model.

A quantitative correlations in the form of mass balance arises also between the two mixture jets. Where these correlations are obviously affected by defined exchange variables such as diffusive mass flow ( $\dot{\mathrm{m}}_{\mathrm{diff}}$ ), as well as by structural factors such as fuel/air mass flow of each burner ( $\dot{\mathrm{m}}_{\text {fuel }}$ , $\left.\dot{\mathrm{m}}_{\mathrm{air}}\right)$, and by the defined Reynolds numbers $(\mathrm{Re})$ of the current mixture jet, and the varied flow $\operatorname{area}(\mathrm{Ai})$.

In this work, the cross-ignition time CIT will be first theoretically determined by a proposed theoretical model, extracted from the physical principles of the above mentioned heat balances.

\section{PROPOSED MODEL FOR THEORETICAL CALCULATION OF CIT FOR TWO ADJACENT BURNERS BASED ON THEIR MUTUAL HEAT BALANCE}

A heat flow from the first active burner is flowing during a cross ignition through the partition wall and simultaneously through the varied contact area $A_{i}$ to the second burner Fig. 7, leading the fresh mixture in the second burner reaching the ignition point after a specific time called CIT. The transferred heat flux ( $\left.\dot{\mathrm{I}}_{\text {trans. }}\right)$ passing through the varied contact area within the exhaust gas flow of the first burner, is affected by the mass diffusive transport ( $\dot{m}_{\text {diff }}$ ), and the flame Emissivity. The total heat balance on the observed control volume is being established through 
$\dot{\mathrm{I}}_{\text {trans., }}$ and the heat produced during the chemical reactions $\left(\dot{\mathrm{I}}_{\text {chem. }}\right)$ Based on Arrhenius low, including the heat losses $\left(\dot{\mathrm{I}}_{\text {loss }}\right)$ in the following main balance equation:

$$
\dot{I}_{\text {tot. }}=\dot{I}_{\text {trans. }}+\dot{I}_{\text {chem }}-\dot{I}_{\text {loss. }}
$$

A homogeneous control volume without gradients of temperature and composition is considered in the control volume. According to Newton's low of heat transfer [9], the amount of the generated heat is then proportional to the temperature difference between ignition temperature $\left(\mathrm{T}_{\mathrm{ig}}\right)$ and initial temperature $\left(\mathrm{T}_{0}\right)$ of the fresh mixture:

$$
\dot{I}_{\text {trans. }}=\alpha_{\text {tot. }} \mathrm{A}_{\mathrm{w} . \text { tot. }}\left(\mathrm{T}_{\mathrm{ig}}-\mathrm{T}_{0}\right)
$$

Thus, the deferential change of temperature in the second burner is calculated by both, the total amount of heat received from the first burner, and the amount of heat developed by the chemical reactions in the second burner.

Heat losses of the second burner is partially transmitted through outer walls to the ambient. The heat loss from this open system will also tack place through the hot exhaust gas mass flow ( $\left.\dot{\mathrm{m}}_{\mathrm{exh}}\right)$ at combustion chamber outlet before the CI- Point. So, the flux of $\dot{I}_{\text {los. }}$ corresponds first to:

$$
\dot{I}_{\text {los. }}=\dot{m}_{\text {exh. } 2} * C p_{\text {exh. } 2} *\left(T_{\text {exh.2 }}-T_{\text {amb. }}\right)
$$

To simplify the calculation, we can here assume that, both of $\dot{\mathrm{m}}_{\mathrm{exh} .}$ and $\mathrm{Cp}_{\mathrm{exh} .}$ are homogeneous at CC-outlet.

The calculation of the released chemical heat $\mathrm{f}$, are performed here through Arrhenius equation.

$$
\begin{aligned}
& \dot{I}_{\text {chem. }}=\left(h_{E}-h_{P}\right) \rho_{2} A e^{\left(-\frac{E}{R T z}\right)} \\
& \Delta h=\left(h_{E}-h_{P}\right)=C p_{\text {fuel }} * \dot{m}_{\text {fuel.burned }} * \Delta T
\end{aligned}
$$

Where $\left(\dot{\mathrm{m}}_{\text {fuel.burned }}\right)$ corresponds here to the proportion of burned fuel.

The Arrhenius term (A $e^{\left(-\frac{E}{R T z}\right)}$ ) represents the reaction rate, which is important to determine the chemical portion of the cross ignition time $\mathrm{CIT}_{\text {chem. }}$.

The theory of the Semenov explosion [9] is being here applied to describe the amount of heat generated in the control volume of the second burner, where no pressure gradients exist.

Since the Schematic- set is an open system, the incoming fuel will be partly ignited and burned out in the combustion chamber. Thus, the model will impact a specific varied control volume of the mixture jet Fig. 7. Based on the above mentioned heat flux in the second burner, the following heat balance will be applied on the $\mathrm{V}_{\text {cont: }}$ :

$$
\int \rho_{2} \mathrm{Cp}_{2} \mathrm{dT} / \mathrm{dt}=V_{\text {cont. }}\left(\dot{\mathrm{I}}_{\text {rad. }}+\dot{\mathrm{I}}_{\text {conv. }}+\dot{\mathrm{I}}_{\text {diff. }}+\dot{\mathrm{I}}_{\text {Chem. }}-\dot{\mathrm{I}}_{\text {los. }}\right)
$$

which results after integrating in the following main- equation:

Whereas the term $\Delta \mathrm{t}$ is corresponded to the calculated CIT. 
These diagrams, Fig. (8, 9 and 10) show almost linear relations, where the CIT is directly proportional to the magnitude of the investigated influence parameters. This direct proportionality is later considered as a determined factor to control the CI while establishing of constructive criteria in low velocity region.

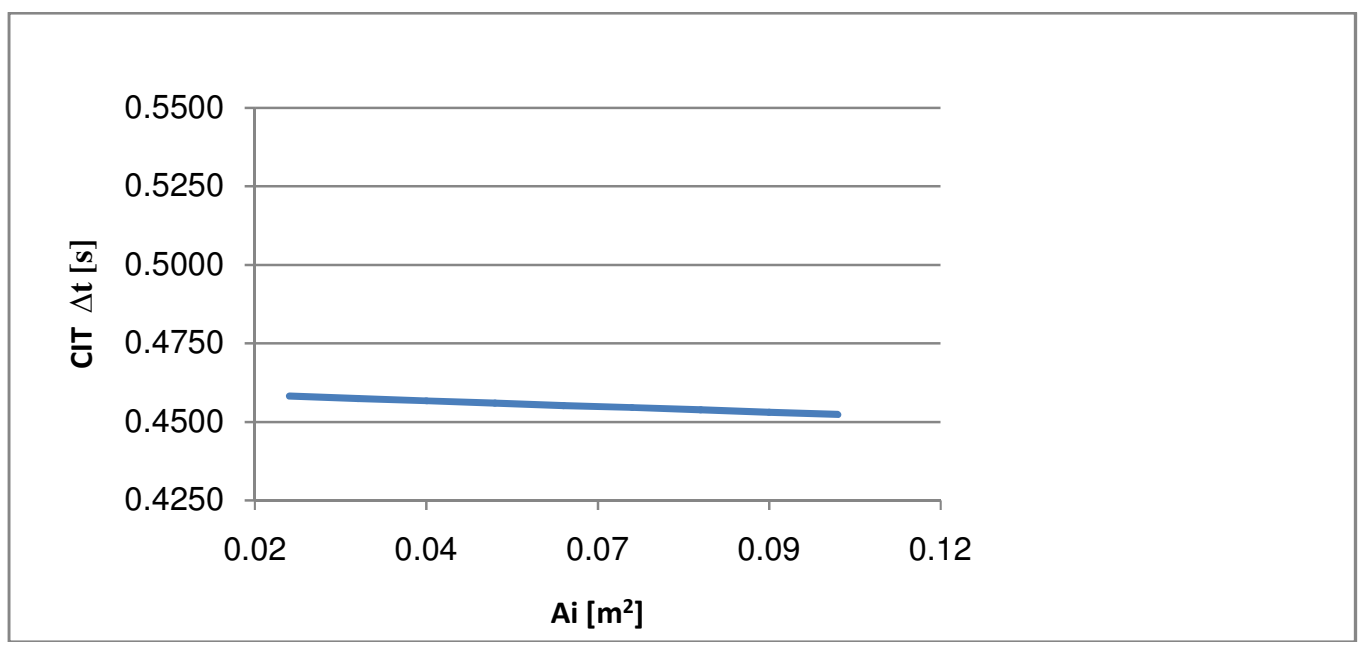

Fig. 8: Effect of different flow areas (Ai) on a cross-ignition process at $\left(\delta_{\mathrm{oi}}=0.5, \Phi_{\mathrm{i}}=1: 15\right)$

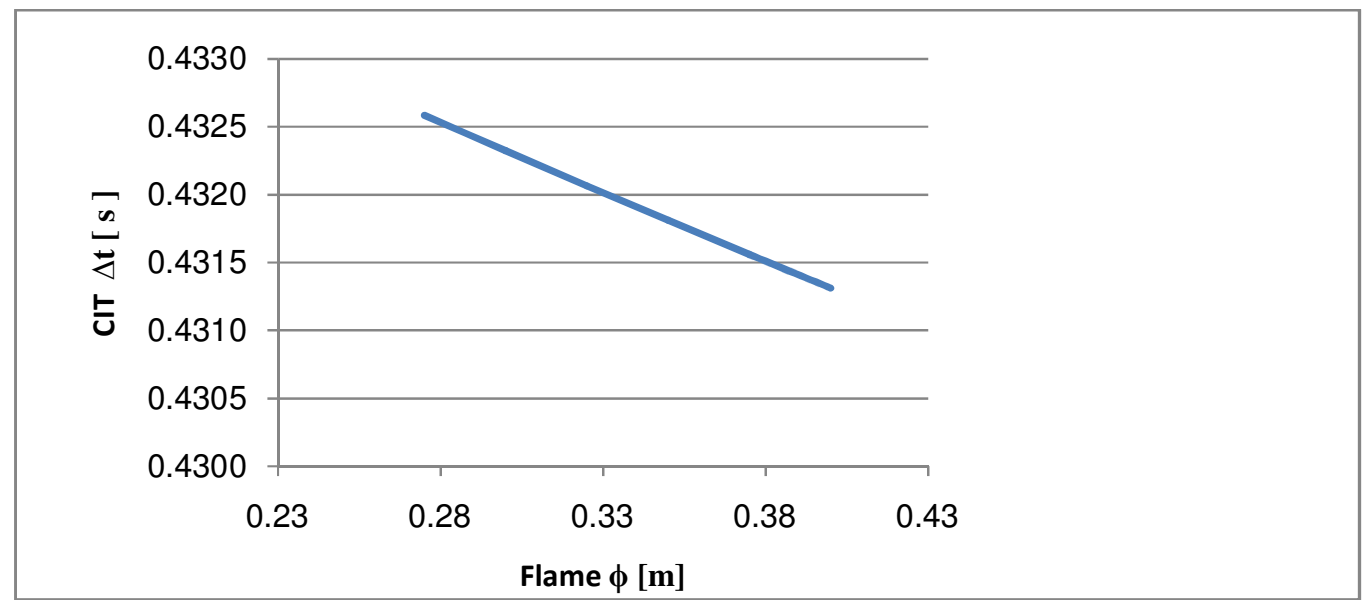

Fig. 9: Effect of different distances or (flame $\phi)$ on a cross-ignition at $\left(\delta_{\mathrm{oi}}=0.5, \mathrm{~A}_{\mathrm{i}}=20 \times 20 \mathrm{~cm}, \Phi_{\mathrm{i}}=1: 15\right)$ 


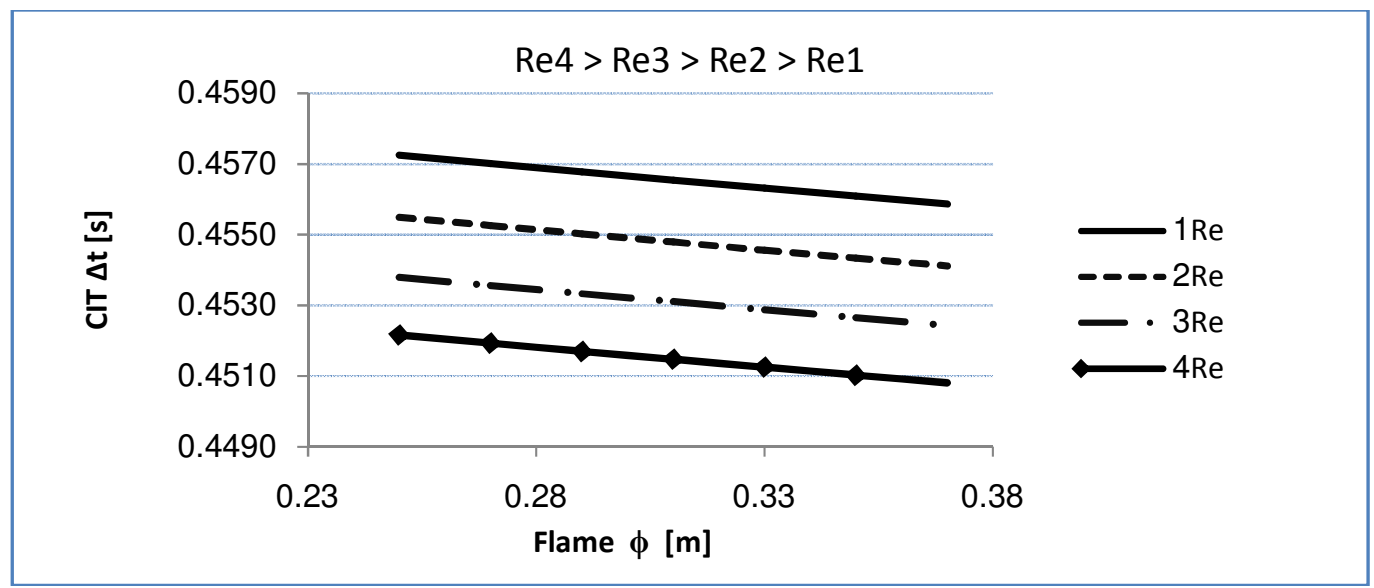

Fig. 10: Effect of various Reynolds numbers on a cross-ignition at $(\delta \mathrm{o}=0.5, \mathrm{Ai}=20$ x $20 \mathrm{~cm}, \Phi=1: 15)$

\section{CONCLUSION}

In this study, physical principles of the heat- transfer were implemented to identify constructive influence parameters, that can control the cross ignition process CI in maltyburner combustors. The primary results were obtained, describing the interacting of the influence parameters on CI in preliminary low velocities producing almost linear relations.

Analyses of these obtained theoretical results show that more investigation are needed for adequate optimization of new criteria for controlling of cross-ignition. Therefore, a simple experimental test- rig should be implemented for investigation of the cross-ignition process to validate these primary results.

But, there are major challenges facing the available technical facilities, due to the high temperatures and fluctuations of the intended measurements. For these reasons, the promising test rig is considered to be an open system, with a constant pressure over the entire test area, and could be supported with visual observations and high-speed recording. For widen the spectrum of the latest theoretical results and getting deeper in the investigations of CI- phenomena, this paper will open the way wide towards implementation of Computational Fluid Dynamic (CFD) Simulation for further study, especially in high velocities and turbulent gradients [11].

\section{REFERENCES}

[1] Heinrich Ostenrath, (1968), Gasturbinen - Treibwerke, Verlag W. Girardet. Essen.

[2] Martin Jordan,(199), Zündung und Verbrennung Vorgemischtenturbulenten Freistrahles, Dissertation.

[3] Jürgen Warnatz and Ulrich Maas, (2001), Verbrennung physikalischer- Chemiekalischer Grundlagen, Modellierung und Simulation, Experimente, Schadstoffentstehung, Springer Verlag.

[4] Hillemans, R.,(1988), Das Strömungs- und Reaktionsfeld sowie Stabilisierungseigenschaften von Drallflammen unter dem Einfluss der inneren Rezirkulationszone, Dissertation Uni. Karlsruhe. 
[5] Prof. Alfonsleben, Wärmetransport, (1988), Vorlesungsskript (I, II) - TU-Berlin.

[6] M. Boileau and G. Staffelbach, (2003), LES of an ignition sequence in a gas turbine engine.

[7] Jassin Fritz, (2003), Flammenrückschlag durch verbrennungsinduziertes Wirbelaufplatzen, Dissertation, Technischen Universität München.

[8] DPG - Arbeitskreis Energie - Bad Honnef, Turbulente Verbrennung, 20. April 2007.

[9] C. Heinrich, (2002), An Annular Combustor Natural Gas Ignition Model Derived from Atmospheric Sector Experiments. ASME 2002.

[10] Klas Kunze, (2003), Untersuchung des thermoakustischen Flammenübertragungsverhaltens in einer Ringbrennkammer, München.

[11] Günther Clauss and Mazen Abu Amro, (2004), Two and Three-Phase Flow Computation For The Optimization Of Oil Skimming Systems, 3rd International Symposium on two-phase flow modeling and experimentation, Pisa. 